\title{
Ambiências urbanas \\ no behaviorismo espacial \\ e na fenomenologia \\ da percepção
}

\author{
Leonardo Oliveira Muniz da Silva, \\ Cristiane Rose de Siqueira Duarte*
}

\begin{abstract}
Resumo Na pesquisa em Arquitetura, as ambiências urbanas são analisadas a partir de categorias espaciais ou da experiência do corpo no mundo. Ambas as perspectivas se conformam na realidade, sugerindo uma superação do dualismo clássico e uma compreensão total das ambiências. Assim, este artigo objetivou estruturar, conceitualmente, as ambiências urbanas por meio de perspectivas metodológicas adversas em um sentido interdisciplinar. A interlocução dos autores demonstrou a necessidade de uma fundação fenomenológica dos espaços, no entanto, abordando estes, primeiramente, por meio de deferências fornecidas pelo "intelectualismo", para a elaboração de hipóteses. Assim, permitiu-se construir uma compreensão das ambiências percebidas e realizadas pelo sujeito e por si mesma, uma unidade espacial própria dotada de valores advindos da mutualidade sujeito-mundo.
\end{abstract}

Palavras-chave: ambiências totais, psicologia ambiental, interdisciplinaridade.

\section{Ambiencias urbanas en el conductismo es- pacial y la fenomenología de la percepción}

Resumen En la investigación arquitectónica, las ambiencias urbanas se analizan desde categorías espaciales o de la experiencia del cuerpo en el mundo. Ambas perspectivas se combinan en la realidad, sugierindo una superación del dualismo clásico y una comprensión completa de las ambiencias. Por lo tanto, el artículo objetiva estructurar conceptualmente las ambiencias urbanas a través de perspectivas adversas en un sentido interdisciplinario. La interlocución de los autores demostró la necesidad de una base fenomenológica de espacios, sin embargo, abordándola, antes, a través de las defensas del "intelectualismo" para la elaboración de hipótesis. Así, se construyó una comprensión de las ambiencias percibidas y realizadas por el sujeto y por sí misma, una unidad espacial propia de valores derivados de la mutualidad sujeto-mundo.

Palabras clave: ambiencias totales, psicología ambiental, interdisciplinariedad.

\section{Urban ambiences by the spatial behaviorism and the phenomenology of perception}

\begin{abstract}
In architecture research, urban ambiences are analyzed from spatial categories or the experience of body in the world. Both perspectives conform in reality, suggesting an overcoming of the classic dualism and a total understanding of ambiences. So, this article aimed to structure, conceptually, the urban ambiences through an adverse methodological perspectives in an interdisciplinary direction. The interlocution of the authors demonstrated the need for a phenomenological foundation of the spaces, however, approaching these, firstly, through deferences provided by "intellectualism" for the elaboration of hypotheses. Thus, it was allowed to construct an understanding of the ambiences as perceived and realized by the subject in the world and by itself, a own spatial unit endowed with values arisen from the mutuality subject-world.
\end{abstract} Keywords: total ambiences, environmental psychology, interdisciplinarity. 
A

pesquisa em Arquitetura e Urbanismo, por definição, é multidisciplinar, no entanto, tende, comumente, a dividir o conhecimento em subdisciplinas particulares (GROAT \& WANG, 2013). Há, nisto, um papel valioso de demonstrar uma variedade de áreas temáticas cujos pontos comuns podem ser focalizados e postos em direção a uma interdisciplinaridade (op. cit.). É o que ocorre, por exemplo, com o campo de estudos de ambiências, sobre o qual se trata o presente artigo abordando seus limiares com a fenomenologia e o behaviorismo espacial.

O estudo de ambiências urbanas - ou seja, das "atmosferas materiais e morais" (Le Petit Robert, 2002) que "englobam as sensações térmicas, lumínicas, sonoras, mas também culturais e subjetivas que envolvem um determinado lugar" (DUARTE et al., 2008 , p. 4) - é uma área temática que se encontra em meio a este desenvolvimento entre diferentes disciplinas. Como as ambiências representam a contextualização sensível dada de um processo contínuo de interação mútua e recíproca entre o ambiente sensível e as atividades humanas (THIBAUD, 2000), ora são contatadas a partir de categorias analíticas subjetivas, como a memória ativada no encontro do indivíduo com o lugar, ora a partir da experiência do corpo próprio no mundo, através da imersão do pesquisador (DUARTE, 2016). Exemplificando: tomemos como referência uma praça. Ela pode ser compreendida por sua morfologia urbana ou seu suporte espacial e, para além disto, sua relevância simbólica para determinados grupos socioculturais que ali realizam atividades e por seus componentes sensíveis como o frescor de seu sombreamento arbóreo, o cheiro de maresia que acusa sua proximidade do mar e o som característico de crianças que ali interagem; uma série de fatores interconectados e que não podem ser estudados separadamente.

Por um lado, tem-se, assim, uma possibilidade de análise pela abordagem interacionista simbólica e afetiva entre o indivíduo e o ambiente, mediada, entre outros fatores, pela cultura e pelas esferas individuais (id., 2010), e, por outro, uma abordagem sensorial do corpo encarnado no lugar (THIBAUD, 2012a). Em outras palavras, é-se possível compreendê-las tanto sob um viés behaviorista espacial (do indivíduo em relação ao espaço), usual da Psicologia Ambiental (GOLLEDGE, 1987; FISCHER, 1994; ELALI, 2009); quanto sob um viés fenomenológico da percepção (do indivíduo [sujeito] no mundo, ocupando-o e se dando através dele [MERLEAU-PONTY, 1994; FISCHER, 1994; THIBAUD, 2012a]).

* Leonardo Oliveira Muniz da Silva é Geógrafo, Doutorando em Arquitetura pela Universidade Federal do Rio de Janeiro - UFRJ, ORCID $<$ https://orcid.org/0000-00033711-9307>. Cristiane Rose de Siqueira Duarte é Arquiteta, com Pós-doutorado na University of California - Berkeley, ORCID $<$ https://orcid.org/0000-00017006-8279>.
Ambas as abordagens possuem relevância para a pesquisa, o planejamento e a gestão urbanos, cada um com suas particularidades. Com um estudo de ambiências do medo, por exemplo, pode-se cartografar as necessidades de melhorias de iluminação pública, quando, sob o viés behaviorista, identifica-se uma sensação compartilhada de insegurança em localidades de baixa luminosidade. Sob o viés fenomenológico, as localidades são atravessadas para um diagnóstico do ponto de vista do usuário permitindo compreender não apenas fatores de influência, mas, principalmente, as singularidades de cada local para que soluções adequadas a cada realidade sejam direcionadas. 
1 Realizou-se uma pesquisa bibliográfica por títulos a partir de bibliotecas físicas e digitais, uma leitura das seções bibliográficas das obras encontradas e, então, um refinamento da busca por obras consideradas primárias ou ordinárias dentro da temática, de acordo com a frequência de citações.
Diante disto, a fim de contribuir com novos direcionamentos da fundamentação da pesquisa em Arquitetura e Urbanismo, o presente artigo tem por objetivo estruturar conceitualmente as ambiências urbanas em sua totalidade através de uma análise das adversas perspectivas teórico-metodológicas behaviorista e fenomenológica, promovendo sua conformação em uma direção interdisciplinar com apoio na psicologia social do ambiente. Nesse sentido, pretende-se identificar os pressupostos teóricos e as estratégias de pesquisa dos estudos de ambiências, da psicologia ambiental, do behaviorismo espacial e da fenomenologia da percepção, apontando suas convergências e divergências. Desta forma, busca-se promover uma interlocução de autores como Thibaud, Fischer, Golledge e Merleau-Ponty para se chegar a uma conformação perspectiva teórica das "ambiências totais".

A estratégia adotada para o alcance destes objetivos, assim, é qualitativa-interpretativa de cunho bibliográfico. Isto significa que obras foram selecionadas segundo critérios preestabelecidos $^{1}$ e, posteriormente, analisadas com uso das técnicas de fichagem de leitura, de autor e de citações, como descritas por Umberto Eco (2007), para uma análise de discurso.

\section{Referencial teórico: as ambiências urbanas em Jean-Paul Thibaud}

As ambiências urbanas surgem de um mecanismo de diálogo entre o sensível e o inteligível (DUARTE et al., 2008). Definida como a atmosfera moral e material que circunda um lugar ou uma pessoa, a ambiência é precisamente a noção que questiona essa divisão e impulsiona sua desconstrução. (THIBAUD, 2012a)

O artigo base para o entendimento das ambiências urbanas aqui selecionado com base nos critérios preestabelecidos anteriormente mencionados se intitula "Contextualisations sensibles de la ville" e teve uma tradução brasileira sob o título "Por uma gramática geradora das ambiências" (THIBAUD, 2012b). Nele se fornece um instrumento teóricoconceitual para o estudo de ambiências compreendendo-as sob, primeiramente, as dinâmicas de interação complementares e mútuas entre o ambiente sensível e as práticas sociais e, posteriormente, os planos de relações espaciais, sensoriais e sociais. Segundo o autor, ambiências são potenciais de contextualização sensível continuamente criados pela determinação mútua entre o ambiente sensível e as práticas sociais nele ocorrentes (id., 2000).

São três as dinâmicas de interação: a aclimatação (1), a qualificação (2) e a recomposição (3). Cada uma delas, associadas aos três tipos de relação: entre o indivíduo e o lugar, entre os sentidos e entre os próprios indivíduos entre si, compreendem os planos fundadores das ambiências: espacialidade, sensorialidade e socialidade.

Sobre as dinâmicas de interação, (1) a aclimatação corresponde a uma conformação entre o ambiente sensível e as práticas sociais de modo que os sujeitos e seu ambiente circundante se confundem. Quer-se dizer que, neste caso, há uma correspondência clara entre o espaço apropriado e as atividades do público nele situado. O indivíduo "entra no clima" do ambiente, que, antes, foi, assim, constituído por outros indivíduos também coprodutores do "clima". (2) A qualificação, por outro lado, consiste em uma inflexão do ambiente à luz das ações e do poder expressivo das atividades do público 
em um local, então, por ele modulado. O ambiente pode fornecer elementos cujas funções idealizadas em seu projeto são subutilizadas e o sentido desses elementos é valorado a partir de uma apropriação dos indivíduos ocupantes por uma oportunidade que o ambiente sensível permite. (3) A recomposição, por fim, diz respeito à produção do público de condições sensíveis para a transformação da ambiência em um campo essencialmente prático. Ou seja, há, neste caso, atividades do público para alterar as precondições ambientais para que outras funções sejam naquele espaço realizadas. Um caso dá-se quando, por exemplo, um grupo de indivíduos se organiza para ocupar uma praça pública, distribuindo-se por toda extensão da praça, para ali realizar um ato político ou uma performance artística que os une.

O cruzamento destas três dinâmicas de interação com os três planos de relação (espacialidade, sensorialidade e socialidade) resulta, assim, no que Thibaud (2000) chamou de nove operações elementares das ambiências (ver Tabela 1).

A operação 1 representa o processo de imersão d o corpo no lugar por uma compatibilidade entre o desejo do indivíduo e a atmosfera local. A operação 2 representa a taticidade desta imersão, através da qual o indivíduo "cede" à ambiência, enquanto a operação 3 se refere à imersão do indivíduo no público que ocupa aquele espaço, que se confunde em extensão com ele. Em relação às ambiências moduladas, primeiramente, tem-se o processo de imersão no ambiente sensível para o conhecimento das oportunidades oferecidas por ele. Em segundo lugar, opera, novamente, sua taticidade a partir de ações do indivíduo que testam a reação do espaço à sua ação. Por último, tem-se o uso apropriado em conjunto com os demais ocupantes. Sobre as ambiências formatadas, a operação 7 delimita o espaço de ação a partir da ocupação, das atividades realizadas pelo público e da reação do ambiente a estas. A operação 8 refere-se ao teste próprio da sensorialidade para uma noção de sua territorialidade; até onde (que limites físicos) as ações do indivíduo impactam ou podem impactar. Finalmente, a operação 9 diz respeito a este impacto em uma relação com os demais ocupantes, alterando a conotação da ambiência para o coletivo. Voltando-se ao exemplo citado para ilustrar a recomposição em um parágrafo anterior

Tabela 1: As nove operações elementares das ambiências. Fonte: Thibaud (2000). (o ato político e a performance artística), pode-se exercitar uma reflexão e verificar a conjugação das nove operações elencadas confirmando o caráter mútuo no conceito de ambiências representado na Figura 1.

\begin{tabular}{|l|c|c|c|}
\hline $\begin{array}{l}\text { Ambiência } \\
\text { (Composição) }=\end{array}$ & $\begin{array}{c}\text { Acordada } \\
\text { (Aclimatação) }\end{array}$ & $\begin{array}{c}\text { Modulada } \\
\text { (Qualificação) }\end{array}$ & $\begin{array}{c}\text { Formatada } \\
\text { (Recomposição) }\end{array}$ \\
\hline $\begin{array}{l}\text { Relação com o lugar } \\
\text { (espacialidade) }\end{array}$ & $\begin{array}{c}\text { Corporificar o lugar } \\
(1)\end{array}$ & $\begin{array}{c}\text { Acomodar-se aos poucos } \\
(4)\end{array}$ & $\begin{array}{c}\text { Dar medida ao lugar } \\
(7)\end{array}$ \\
\hline $\begin{array}{l}\text { Relação com os sentidos } \\
\text { (sensorialidade) }\end{array}$ & $\begin{array}{c}\text { Tomar-se de afeição } \\
(2)\end{array}$ & $\begin{array}{c}\text { Colocar o espaço à prova } \\
(5)\end{array}$ & $\begin{array}{c}\text { Colocar a cognição à prova } \\
(8)\end{array}$ \\
\hline $\begin{array}{l}\text { Relação com os outros } \\
\text { (socialidade) }\end{array}$ & Fundir-se à paisagem & $\begin{array}{c}\text { Fazer-se presente } \\
(6)\end{array}$ & $\begin{array}{c}\text { Dar tonalidade às situações } \\
(9)\end{array}$ \\
\hline
\end{tabular}



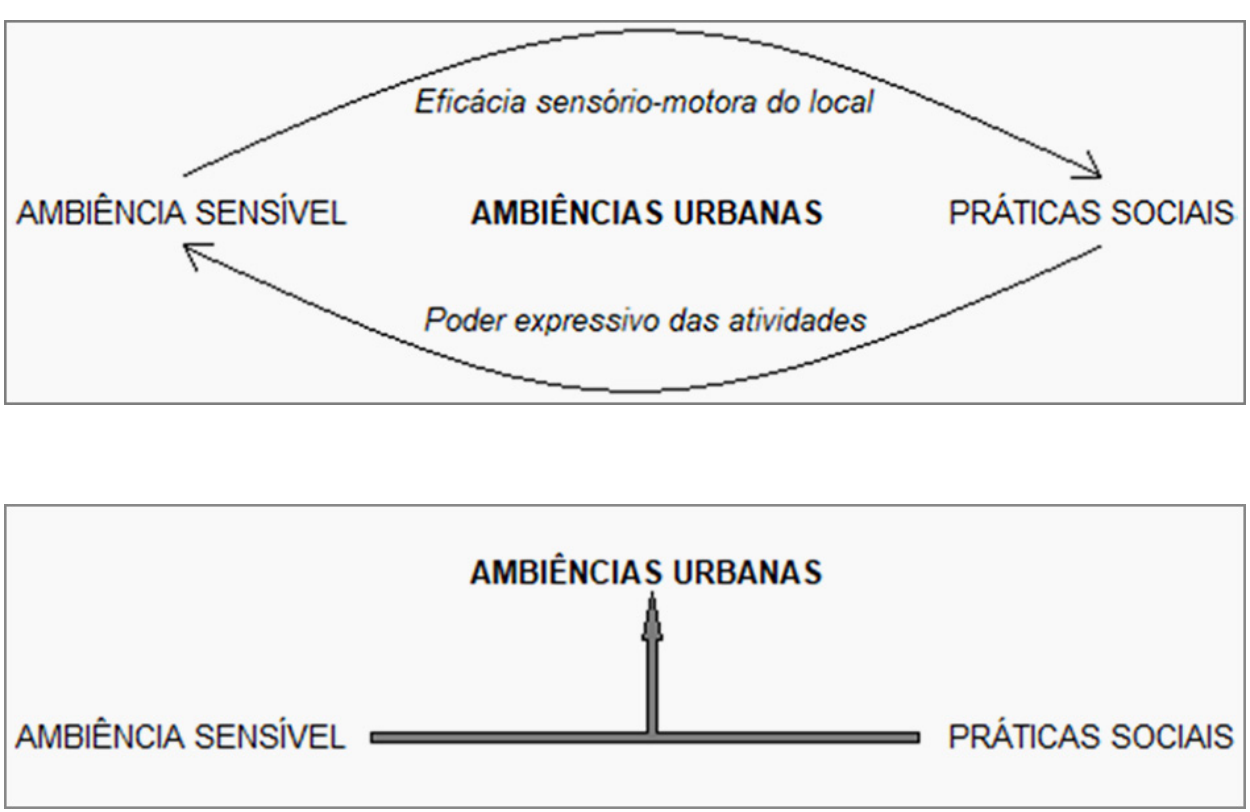

Figura 1 (topo): Contextualização sensível fundadora das ambiências. Fonte: Thibaud (2000).

Figura 2: Proposta de representação do conceito de ambiências com ênfase na mutualidade. Fonte: Acervo próprio. Baseado em Thibaud (2000).
Por conta disto, torna-se claro que não se defendem hipóteses relacionadas a um "pontapé inicial" nas relações ou interações. As nove operações elementares das ambiências compõem a essência das ambiências, denotando alguma ciclicidade, porém, de maneira nenhuma, sugerindo um padrão de comportamento ambiental e de determinação dos valores e das atitudes humanas em seus quadros sensíveis. 0 ambiente sensível e as práticas sociais se encontram, como na proposta alternativa apresentada na Figura 2, e, assim, as diferentes dinâmicas de interação possuem um caráter de instrumentação para a compreensão das ambiências sem esgotálas: identificar as ambiências dos espaços urbanos passa necessariamente por uma experiência sensorial, por uma observação detalhada do devir urbano, por uma resposta dos ambientes às ações humanas no espaço físico, por uma avaliação de seus usuários e por uma constituição de atmosferas sob uma perspectiva psicossocial que, em maior ou menor grau, relacionam-se com o comportamento humano, usuário final dos projetos de arquitetura e urbanismo.

\section{A psicologia ambiental em Gustave-Nicolas Fischer}

A Psicologia Ambiental é, em linhas gerais, o campo de estudos das interrelações indivíduo-ambiente ou, nas palavras de Hartmut Günther (2005, p. 179), "das relações (recíprocas) entre os fenômenos psicológicos (comportamentos e estados subjetivos) e as variáveis ambientais físicas". É, assim, próxima e relaciona-se ao estudo de ambiências, como demonstra Gleici Azambuja Elali (2009), tendo sido também objeto de estudo de Jean-Paul Thibaud em um artigo publicado na revista de psicologia da Universidade de São Paulo (Psicologia USP) em 2005. Segundo Fischer (1994), a psicologia ambiental representa um novo domínio do saber em ciências humanas e revela-se sob dois diferentes ângulos de abordagem: o bioecológico e o psicossocial. 
2 Refere-se aqui à teoria interpretativa da cultura, de Clifford Geertz (1989), onde cultura é entendida como um conjunto menos ou mais articulado de teias de significado tecidas pelo homem e pelas quais o mesmo se encontra amarrado. Segundo Ortner (2007), através dessa teoria, permitiu-se um método interpretativo para compreender a construção cultural da subjetividade, pois os processos culturais se dão como formas simbólicas públicas que expressam e modelam significado para os atores engajados no fluxo contínuo da vida social.
A Psicologia Ambiental Bioecológica (PAB) corresponde ao campo de pesquisa tradicional em psicologia ambiental. Ela tem por base teórica a escola do pensamento psicológico clássico, behaviorista, ou seja, aquela que busca compreender a organização espacial do comportamento sob a lógica estímulo-resposta, onde componentes ambientais são considerados estimulantes a uma determinada forma de agir sobre o espaço. A PAB corresponde, portanto, a estudos de comportamentos humanos considerados simples, como por exemplo, dos deslocamentos e decisões espaciais baseados na localização de recursos e eventos desejados ou indesejados realizando análises classificatórias para aplicação em escalas geralmente regionais, como aborda Reginald Georg Golledge (1987). Mas também inclui em seu campo estudos de comportamentos humanos locais considerados como sendo de maior complexidade, como aqueles relativos ao estresse:

Muitos estudos debruçaram-se sobre os aspectos do espaço tais como a densidade, o ruído, o calor, etc., considerados como susceptíveis de provocar um comportamento estressante. [...] Ao lado dos estudos sobre o espaço e o stress, outros destacaram a psicopatologia do espaço [...] evidenciado pelo fato de certos espaços provocarem medos mórbidos e, mais precisamente, aquilo a que se chama fobias espaciais, sendo as duas mais conhecidas a agorafobia e a claustrofobia. (FISCHER, 1994, p. 50-51)

Este ângulo de abordagem permite revelar as correspondências e as interações que os indivíduos estabelecem com os lugares, no entanto, não compreendem a complexidade dos comportamentos e das atividades em si, pois, como critica a fenomenologia: "ele [o real] não espera nossos juízos para anexar a si os fenômenos mais aberrantes, nem para rejeitar nossas imaginações mais verossímeis" (MERLEAU-PONTY, 1994, p. 6). Ou seja, a ação humana não pode ser reduzida a precondições espaciais, tampouco o espaço pode ser reduzido àquilo que avaliam os indivíduos. Com base (parcial) nesta crítica, desenvolveu-se a Psicologia Social do Ambiente (PAS), explorando as dimensões psicológica, cultural e social nos espaços. A PAS tem por base teórica a escola do pensamento cultural, humanista, partindo de uma concepção fenomenológica do espaço, porém, utilizando os métodos e técnicas de pesquisa qualitativa-interpretativa baseada na teoria geertziana ${ }^{2}$. Quer-se dizer que se esboçou uma aproximação à fenomenologia da percepção de Maurice Merleau-Ponty, que "mostrou a importância da relação entre espacialidade e corporeidade e separou a ideia de espaço vivido e conhecido" (FISCHER, 1994, p. 17), considerou-se "visualizar o indivíduo através de sua inserção nos lugares" (op. cit., p. 15) e, por fim, adotou-se como premissa que "a maneira como uma sociedade utiliza o espaço corresponde ao sistema de valores que é o seu e que ela desencadeia para responder às suas necessidades fundamentais, às suas atividades e às relações entre os seus membros" (op. cit., p. 64). É-se, assim, uma abordagem interacionista simbólica e afetiva da interrelação indivíduo-ambiente podendo, segundo Elali (2009), ser interpretada pelo conceito de ambiência mesmo tendo sido elaborada à luz de conceitos outros, devido à conotação emocional das situações vividas no lugar.

Nesta perspectiva, considera-se desde logo que os lugares em que vivemos e trabalhamos moldam de algum modo as nossas maneiras de ser e os nossos comportamentos, dado que nós próprios nos constituímos nas relações que com eles mantemos. [...] Isto permitir-nos-á apreender o espaço segundo duas componentes correlativas: por um lado, o quadro físico no qual nos encontramos e que nos rodeia é o conjunto dos lugares organizados nos quais evoluímos e que formam, cada um 
Figura 3: Os três componentes da atitude. Fonte: Triandis (1971 apud. Golledge, 1987). deles, um tipo dado de território; por outro, o corpo próprio, que ocupa um espaço bem determinado como espaço ocupado pelo nosso corpo [o espaço pessoal]. (FISCHER, 1994, p. 9-10; p. 21)

Assim, esta abordagem inclui as noções de territorialidade e corporeidade analisando a "psicologia do espaço" através da experiência sensível e da extensão metafórica dos corpos - todos elementos encontrados em Thibaud (2000).

\section{O behaviorismo espacial em Reginald George Golledge}

Como já antecipado, o behaviorismo espacial deriva do pensamento clássico sob a lógica estímulo-resposta, e o faz unilateralmente, para compreender a organização espacial do comportamento humano ou, mais especificamente, do que o autor chama de "atitude": o que, diferentemente do conceito de percepção - dada com o contato imediato entre o corpo e o espaço -, "contém a noção de que é aprendida, que predispõe à ação e que é relativamente invariante ao longo do tempo [porque composto por afetos e ativações menos ou mais intencionais]" (GOLLEDGE, 1987, p. 49). Ver Figura 3.

Diante da limitação deste determinismo unilateral enunciada pela escola do pensamento fenomenológico, é possível, no entanto, resgatar e adaptar a lógica estímulo-resposta para uma perspectiva mútua de "ação-reação" simultânea, considerando que o ambiente, por sua projeção e lócus, é igualmente responsável pela ação impulsionada pelo(s) indivíduo(s). Em outras palavras, as respostas do ambiente a uma determinada ação humana, como, por exemplo, o eco provocado por um som emitido, não são observadas meramente como reações estimuladas pela voz ou outra fonte sonora, porque, anteriormente à ação humana de emissão do som, o ambiente já está projetado de forma a determinar o eco tal como o ocorrente. O ambiente estimulado é, assim, ao mesmo tempo, estimulante, ou, nas palavras de Merleau-Ponty (1994, p. 328), o espaço é um meio "espacializado e espacializante". Cumpre mencionar, como fez Golledge (1987), neste sentido, o trabalho de David Seamon (1982), para quem a pesquisa convencional em psicologia ambiental aceitou, por muito tempo, pressupostos que estão fora do tecido real do comportamento e da experiência ambiental e que a fenomenologia retomou revitalizando seus fundamentos ontológicos, epistemológicos

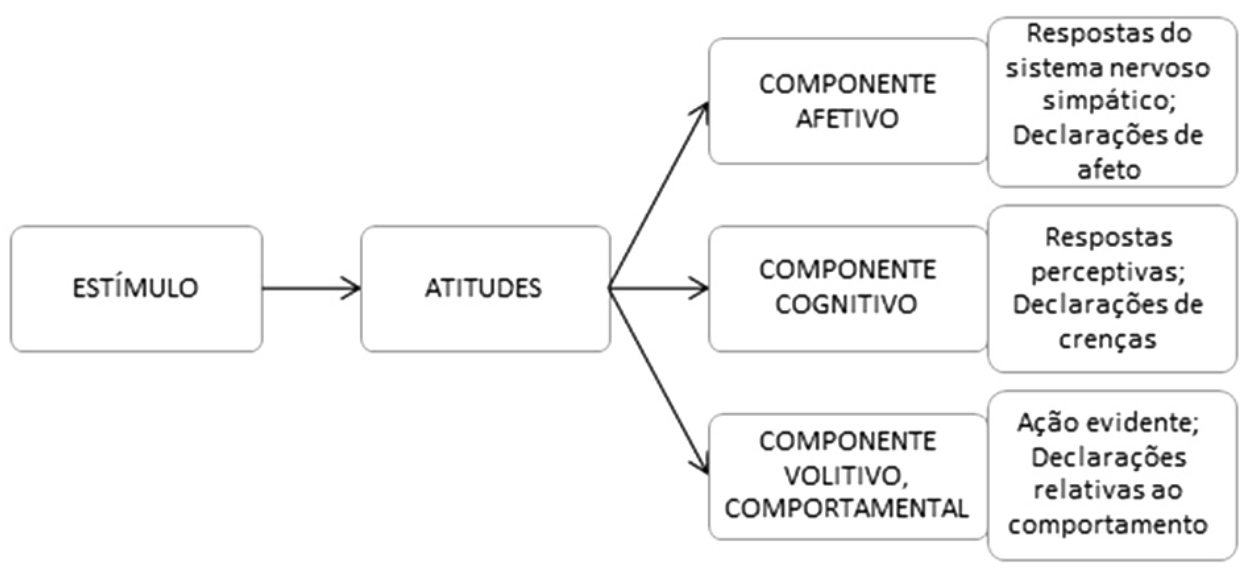


e metodológicos sugerindo o exame "da percepção sensível ao encontro místico com a natureza, dos aspectos mundanos e habituais do mundo da vida" (op. cit., p. 136).

Golledge (1987) reconhece esta crítica, considera-a para um desenvolvimento da pesquisa analítica behaviorista espacial e defende, assim, o estímulo-resposta não como uma verdade científica, mas, sim, uma utilidade para a compreensão das atitudes humanas sobre determinados ambientes. Ele coloca que a abordagem behaviorista, por vezes, chamada socioespacial é "um paradigma para a compreensão das configurações espaciais humanas do comportamento [...] que engloba um conjunto complexo de variáveis e suas relações funcionais" (op. cit., p. 11). Ela é atravessada por processos psicológicos que orientam resultados comportamentais como movimentos espaciais e decisões locacionais. "Assim, pode-se propor um modelo de interface comportamental homem-ambiente" (op. cit., p. 11). À título de exemplificação, aplicações desta forma de análise presentes até hoje podem ser verificadas na escolha de percursos onde, por uma sensação de medo, prefere-se utilizar rotas mais distantes (e mais seguras sob a ótica do transeunte) para se chegar a um determinado destino. Com base, portanto, na notação de frequência (repetição do fenômeno) de determinados percursos, poder-se-ia identificar localidades para investigação e definição de quais variáveis ali presentes "estimulam" a decisão do transeunte. Neste sentido, os três componentes da atitude apresentados na Figura 3 confirmam sua utilidade e relevância.

Na busca por estas lógicas e modelos, que não abarcam a questão moral, por exemplo, Golledge (1987) explicita sua base na tradição positivista e elenca, assim, as características ainda consideradas, justificando-as sobre a necessidade de um rigor científico. Então, enumera as seguintes táticas de estudo: (1) desenho experimental; (2) procedimentos de armazenamento de dados; (3) pesquisas de validação; (4) seleção de métodos analíticos; (5) opção por uma base epistemológica analítica moderna; (6) modelagem de estruturas de conhecimento do homem e do ambiente (op. cit., p. 10). Nos estudos de psicologia ambiental, ainda na última década, há muitas referências principalmente às táticas de número 1 e 6 para o objetivo de se compreender as relações entre indivíduo e ambiente, podendo citarmos aqui Piña \& Zaragoza Ortega (2003) para exemplificação. Em relação às táticas 2, 4 e 5, pode-se citar, em menor grau, a utilização de cartografias e a constituição de mapas cognitivos espaciais (pode-se citar, neste caso, o próprio Golledge [1987]). A tática 3 pode se referir a uma comparação entre dados adquiridos por um sujeito experiencial e fatos anteriormente verificados, ou seja, uma possibilidade para a identificação de ressignificações de lugar ou de estigmas espaciais, por exemplo.

Assim, explicitamos a escola de pensamento, as formas de análise e as possibilidades de aplicação advindas do behaviorismo espacial que, cumpre notar, reconhece a necessidade, em Golledge (1987), mesmo diante deste cenário positivista, de se incluir variáveis relativas a subjetividades e cultura, que são descartadas de seus estudos por se ter objetivos outros. Ao último capítulo da obra referência aqui citada, apresentase, inclusive, as alternativas e o futuro da pesquisa a partir de: um interacionismo ou transacionismo entre pessoa-ambiente (este termo é presente, por exemplo, em Moser [2003], psicólogo ambiental crítico ao behaviorismo); ideias humanistas, onde a noção de espaço deve ser substituída pela noção de lugar, e fenomenológicas, onde se cita Seamon (1982) como a possibilidade de estudos da experiência humana, da fenomenologia do ambiente físico (sensível) e um relacionamento entre estas duas 
acepções; por fim, Golledge (1987) cita ainda como alternativa a teoria social originária do pensamento de Marx, a partir do qual pode-se revelar contrastes sociais com base, então, no comportamento (GOLLEDGE, 1987). Porque, em suma, é a percepção sensorial do ambiente que permite apreendê-lo em imediato e, assim, valorá-lo, condicionando a relação afetiva do indivíduo com o lugar e a avaliação de quais modos de conduta são ali preferíveis (op. cit.). "Percepção" é um conceito fundamental na abordagem behaviorista e é sobre o qual se torna mais clara a ruptura do pensamento fenomenológico com a psicologia clássica.

\section{Percepção em Golledge}

Golledge (1987) entende a percepção como algo complexo, citando Werner \& Kaplan (1963), compreendendo-a como um processo pelo qual um ou mais indivíduos interpretam, categorizam e transformam um determinado estímulo. Por este suporte, do estímulo que, no caso, é apreendido do ambiente, conclui, então, que a percepção necessariamente passa por uma perspectiva experiencial onde os sentidos humanos apreendem informações ambientais, devendo, assim, ser atribuída a esta perspectiva: "Isto é percepção. Diz respeito à apreensão imediata do ambiente estimulante por um ou mais dos sentidos. Ocorre devido à presença de um objeto. Está intimamente ligada a eventos nos entornos imediatos e, em geral, aos seus comportamentos" (GOLLEDGE, 1987, p. 37). Assim, associa ainda à cognição e a pré-condições socioculturais:

Cognição refere-se ao meio em que a informação é recebida, armazenada e organizada no cérebro e encontra com o conhecimento acumulado e seus valores atribuídos; ele diz respeito a uma ligação do presente com o passado e com o projeto que se tem de futuro. [...] Crenças pessoais, valores e outras conotações sociais, assim, parecem influenciar os atributos do que é percebido. Trabalhando em conjunto, esses fatores, às vezes, determinam até que ponto partes da estrutura de conhecimento do indivíduo são retidas, modificadas ou excluídas. (op. cit., 1987, p. 38; p. 43)

É-se possível, finalmente, minuciar uma adaptação do que representa a Figura 3. A lógica estímulo-resposta é considerada apenas como ponto de partida para seu desenvolvimento teórico, sendo aplicada por Golledge (1987) por conta dos objetivos ligados à conduta espacial dos indivíduos em um sentido preditivo; pela opção em trabalhar especificamente com o que, segundo Fischer (1994), seriam as condutas mais simples do comportamento humano, compreendidas a partir de métodos de natureza quantitativa com o armazenamento de dados provenientes de uma certa vigilância, identificando-se padrões. O estímulo-resposta como ponto de partida representa a descoberta de um contexto sensível amplo para o qual a pesquisa social deve caminhar e mergulhar-se sob perspectivas qualitativas usuais das ciências humanas. Pode-se apontar, com apoio no que nos ensina Fischer (1994), que Golledge (1987) dá ordem prática à psicologia ambiental bioecológica ao tempo em que direciona a ordem teórica à psicologia social do ambiente (carregando com ela a perspectiva interacionista mediada por valores culturais, simbólicos, do afeto e do comportamento, a mesma que pode ser visualizada segundo Elali [2009] através do conceito de ambiência). 


\section{A fenomenologia da percepção em Maurice Merleau-Ponty}

A fenomenologia recusa lógicas associativas como as vinculadas à psicologia clássica resgatadas pelo behaviorismo espacial. Segundo Golledge (1987, p. 308), "a aceitação de uma base interacionista para a pesquisa behaviorista permite a investigação de situações mediadoras das relações diretas entre pessoa e ambiente". Assim, os aspectos sociais e culturais, por exemplo, seriam condicionantes espacializados que difeririam preferências e escolhas de comportamento. Seriam aspectos associativos de intermediação entre o indivíduo e o ambiente, capturados ou não pela estrutura corpórea perceptiva, sobre os quais se estabelecem as dinâmicas interativas. Na fenomenologia de Merleau-Ponty, no entanto, estes ou quaisquer outros condicionantes de natureza analítica, como os psicológicos, são reducionistas, pois "reintroduzem em sua descrição relações que pertencem ao mundo objetivo" confrontando os estímulos materiais do mundo com a consciência perceptiva e moral (MERLEAU-PONTY, 1994, p. 40). Ou seja, afasta-se de uma perspectiva experiencial "pura", sensível, por um enviesamento intelectivo, ao qual Merleau-Ponty também se apresenta crítico:

Certamente, o intelectualismo representa um progresso na tomada de consciência. [...]. Mas, como ele não está envolvido no sistema [da experiência], as relações continuam a ser aquilo que eram no empirismo: relações de causalidade desdobradas no plano dos acontecimentos cósmicos. (op. cit., 1994, p. 280)

Esta passagem, para além do intelectualismo e da associação, apresenta outros dois dos principais pontos focais da crítica fenomenológica às escolas do pensamento clássico: a busca por leis de causalidade e a noção de espaço como um mero "ambiente das coisas". Porque, primeiramente:

A fenomenologia é o estudo das essências [...]. É a tentativa de uma descrição direta de nossa experiência tal como ela é. E sem nenhuma deferência à sua gênese psicológica e às explicações causais que o cientista, o historiador ou o sociólogo dela possam fornecer [...]. É em nós mesmos que encontramos a unidade da fenomenologia e seu verdadeiro sentido. [...]. Eu não sou o resultado ou o entrecruzamento de múltiplas causalidades que determinam meu corpo ou meu "psiquismo" [...]. Eu sou a fonte absoluta; minha experiência não provém de meus antecedentes, de meu ambiente físico e social, ela caminha em direção a eles e os sustenta, pois sou eu quem faz ser para mim (e portanto ser no único sentido que a palavra possa ter para mim) essa tradição que escolho retomar. (op. cit., 1994, p. 1-4)

E, em relação ao espaço, ele:

Não é o ambiente (real ou lógico) em que as coisas se dispõem, mas o meio pelo qual a posição das coisas se torna possivel. Quer dizer, [...] devemos pensá-lo como a potência universal das conexões. Portanto, ou eu não reflito, vivo nas coisas e considero vagamente o espaço ora como o ambiente das coisas, ora como seu atributo comum, ou então eu reflito, retomo o espaço em sua fonte, penso atualmente as relações que estão sob essa palavra, e percebo então que elas só vivem por um sujeito que as trace e as suporte, passo do espaço especializado ao espaço espacializante. (op. cit., 1994, p. 328) 
Diante disto, pode-se afirmar que a fenomenologia funda uma escola do pensamento crítico ao pensamento clássico e que coloca no centro das questões a corporeidade, o eu empírico-perceptivo-sensorial, isto, portanto, encarnado em um espaço que é suporte, mas não meramente por constar de um enquadramento físico e, sim, fundamentalmente, por se tratar do meio através do qual as relações se dão e os fenômenos se integram ao real sensível. Assim:

O mundo que eu distinguiria de mim enquanto soma de coisas ou de processos ligados por relações de causalidade, eu redescubro "em mim" enquanto horizonte permanente de todas as minhas cogitationes e como uma dimensão em relação à qual eu não deixo de me situar. O verdadeiro Cogito não define a existência do sujeito pelo pensamento de existir que ele tem, não converte a certeza do mundo em certeza do pensamento do mundo e, enfim, não substitui o próprio mundo pela significação mundo. Ele reconhece, ao contrário, meu próprio pensamento como um fato inalienável, e elimina qualquer espécie de idealismo revelando-me como "ser no mundo". (op. cit., 1994, p. 9)

Isto leva à compreensão de que o pensamento fenomenológico parte de uma unidade indivíduo-ambiente, e não de uma relação entre objetos isoláveis que, na realidade, estão imbricados, observados um sobre o outro com um certo grau de distância. Esta retomada do pensamento é a condição para o objetivo da fenomenologia em "colocar em suspenso, para compreender, as afirmações da atitude natural [...], e cujo esforço todo consiste em reencontrar este contato ingênuo com o mundo" (op. cit.). Quer-se dizer que a base fenomenológica está na imersão do corpo no espaço através de uma multissensorialidade que, cumpre notar, tem-se perdida não apenas por um intelectualismo científico, como também pelo acelerado ritmo urbano econômico do mundo moderno (BAUMAN \& DONSKIS, 2014; SIMMEL, 1973). O foco, no campo fenomenal, retoma-se, está no "sentir", nas condições da percepção "reduzida" à sensorialidade, ao conhecimento tácito temporal, como na fundação das ambiências; na mutualidade corpo(sensorial)-ambiente-socialidade; no potencial de contextualização sensível para sensações compartilhadas.

\section{Percepção em Merleau-Ponty}

O estudo da percepção, segundo Merleau-Ponty (2015, p. 31; p. 52; p. 76):

Termina por revelar que o mundo percebido não é uma soma de objetos, no sentido que as ciências dão a esta palavra [...]. Não podemos, por conseguinte, aplicar à percepção a distinção clássica da forma e da matéria, nem conceber o sujeito que percebe como uma consciência que "interpreta", "decifra" ou "ordena" uma matéria sensivel da qual ela possuiria a lei ideal. [...]. A evidência não é jamais apodítica nem o pensamento intemporal, embora haja um progresso na objetivação e o pensamento valha sempre para mais de um instante. [...]. O mundo percebido seria o fundo sempre pressuposto por toda racionalidade, todo valor e toda existência. [...] Não há aqui, portanto, nenhuma destruição do absoluto ou da racionalidade, senão do absoluto e da racionalidade separados. [...]. Perceber é tornar algo presente a si com a ajuda do corpo, tendo a coisa sempre o seu lugar em um horizonte de mundo e consistindo a decifração em recolocar cada detalhe nos horizontes perceptivos que Ihe convier. 
Portanto, apesar da visão crítica e de um novo direcionamento dos estudos de percepção realizados pela psicologia, corrobora-se, com a fundação sensível dos espaços sob o viés da experiência, a psicologia "em seu terreno próprio" (MERLEAU-PONTY, 2015, p. 20), uma vez que a consequência filosófica da retomada à natureza da percepção por uma corporeidade é a impossibilidade de se distinguir percepção e sensação. "A antiga psicologia postulava, como dados primeiros da consciência, sensações que supostamente correspondiam, termo a termo, às excitações locais dos aparelhos sensoriais" (op. cit., p. 21). Assim, um estudo de sensações compartilhadas como as ambiências é um estudo de percepção no sentido fenomenológico e, como tal, tem por desafio a conjugação do lado sensível e do lado intelectivo através da construção de descrições narrativas.

\section{Conclusões: de volta às ambiências, por ambiências totais}

Diante das explanações aqui realizadas sobre a psicologia ambiental, o behaviorismo espacial e a fenomenologia, identificamos três pontos de divergência fundamentais que, em maior ou menor grau, se encontram nos estudos de ambiências.

O primeiro ponto, relativo aos seus fundamentos teóricos, diz respeito, de um lado, da fenomenologia, à mutualidade entre o sujeito e o mundo e ao caráter autêntico das ações humanas. Enquanto isso, para o behaviorismo espacial, o que interessa é o relacionamento causal entre os dois objetos tendo categorias outras como elementos de intermediação. O behaviorismo espacial, portanto, alinha-se a um pensamento tradicional determinista e, quando o supera, ampara-se na ótica interacionista e simbólica para a qual as ações humanas são derivadas de fatores como a cultura.

O segundo ponto se refere aos modos de operação da fenomenologia e do behaviorismo espacial. Enquanto a fenomenologia busca relatos do espaço, do tempo e do mundo vividos (MERLEAU-PONTY, 1994, p. 1), o behaviorismo espacial busca registros de ocorrências para inclusão em modelos de interface homem-ambiente (GOLLEDGE, 1987). Os relatos, então, convergem com as descrições narrativas utilizadas em estudos de ambiências no âmbito de pesquisas em Arquitetura e Urbanismo (cf. DUARTE, 2010). Já a configuração de modelos behavioristas não é, de nenhuma maneira, utilizada pelos estudos de ambiências; no entanto, por outro lado, permitem a elaboração de hipóteses a serem testadas/investigadas a partir da compreensão dos contextos sensíveis de um fenômeno relevante posto em análise.

Por fim, o terceiro ponto culmina na compreensão do conceito-chave para ambas as perspectivas: a percepção. Para ambos, a percepção se dá através da recepção de aspectos advindos de uma realidade contatada por um corpo, então, sensorial. A diferença encontrada em suas definições está na consideração fenomenológica de que o sujeito, por si, experimenta as sensações perceptivas através do espaço, enquanto, para o behaviorismo, o indivíduo experimenta sensações que são relativas ao espaço, que é um estimulante. Aceitando-se a autenticidade das ações humanas, pode-se afirmar que elas contêm diferentes graus de intencionalidade e, portanto, podem estar menos ou mais ligadas a um certo incentivo ambiental. Entende-se, assim, que as duas perspectivas coexistem na realidade. É desta forma, inclusive, que Tuan (1980) conceitua percepção: "é tanto a resposta dos sentidos aos estímulos externos, como a atividade proposital, na qual certos fenômenos são claramente registrados, enquanto outros retrocedem para a sombra ou são bloqueados". (op. cit., p. 4) 


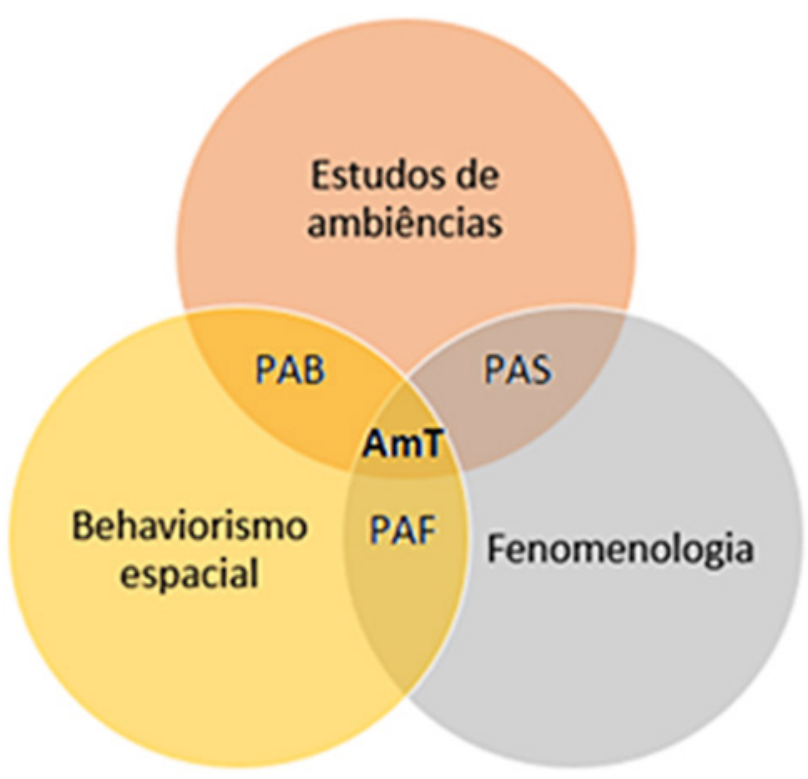

Figura 4: Conformação perspectiva teórica das ambiências. Fonte: Acervo próprio.
Retomando Gustave-N. Fischer (1994), pode-se afirmar que a organização espacial do comportamento verificada em Golledge (1987) compõe e é composta pela psicologia do ambiente sob o ângulo bioecológico, útil para a formulação de hipóteses de estudos de ambiências e comportamento. Já a abordagem psicossocial do ambiente, identificando a necessidade de se privilegiar "a análise dos processos de interações homem-espaço, mostrando [...] como a estrutura do comportamento de cada qual se investe por meio da expressão de sentimentos, de motivações, de percepções" (op. cit., p. 18), dialoga mais fortemente com a instrumentação dos estudos de ambiências urbanas, como em Duarte et al. (2008) e Duarte (2016), que encontra em Thibaud (2000) grande ressonância.

Mais explicitamente, para o campo da Arquitetura, as ambiências surgem como uma categoria analítica fundamental, inclusive no que tange aos objetivos de conforto, se compreendemos este como sendo essencialmente apreendido pela imersão do corpo no espaço, o que o é. A busca fenomenológica que as ambiências urbanas trazem em relação ao espaço, por esse resgate à "atitude natural", se então aceita, coloca um novo paradigma para o pensar arquitetônico que permitirá o reencontro do sujeito com seu corpo próprio no mundo e a noção de que este mundo (percebido) também percebe as ações nele correntes, pois estas se dão através de sua unidade subjetiva psíquica e motora. É sobre esta noção que a "psicologia ambiental fenomenológica" (PAF) se desenvolve e, finalmente, permitindo-nos ilustrar a conformação dos campos e subcampos do conhecimento que abordamos (Figura 4).

A Psicologia Ambiental sob o ângulo bioecológico (PAB) constitui e é constituída por estudos onde o valor almejado reside nas relações comportamentais (behavioristas) através de suas associações com as ambiências. A Psicologia Social do Ambiente (PAS) se reconhece na busca por um entendimento do sensível em um sentido crítico aos modelos baseados em estímulos. A Psicologia Ambiental fenomenológica (PAF) acaba 
por manter a tradição da pesquisa behaviorista, no entanto, assumindo proposições teóricas da fenomenologia complexificando a interpretação dos relacionamentos entre os objetos. Finalmente, assim, as ambiências totais (AmT) surgem da integração de todas estas possibilidades que não perdem seu valor central: as determinações mútuas entre a espacialidade, a sensorialidade e a socialidade, além de um interacionismo necessário para compreensão das tonalidades afetivas. Abre-se, com isto, o leque de "subdisciplinas" dos estudos das ambiências, bem como um direcionamento à sua interdisciplinaridade ou mesmo transdisciplinaridade.

Para pôr sob os moldes convencionais da pesquisa científica, a partir da base analítica, das deferências causais fornecidas por psicólogos, sociólogos, antropólogos, entre outros, há-se um desenho inicial, condicionante de hipóteses, do "contexto de descoberta" dos fenômenos, que figura, na realidade, o passo primeiro para uma melhor representação de problemas abertos e complexos, mas sem constituí-lo como fim ou declaração de fato (DORST, 2011, p. 523-524). Os estudos de ambiências, assim, optam, então, pelo "método abdutivo" (op. cit.), onde as deferências ou o contexto de descoberta são a base de um pensamento produtivo que terá objetivos e formas de análise formatados e reformatados entre teoria e campo; embasamento teórico e imersão. O "como" e o "princípio de trabalho" das pesquisas neste método serão continuamente construídos entre a diversidade de saberes até que um determinado valor (este sim configurado como a finalidade da pesquisa) seja alcançado. Este valor configurará a qualidade de ambiência.

\section{Agradecimentos}

O presente trabalho foi realizado com apoio da Coordenação de Aperfeiçoamento de Pessoal de Nível Superior - Brasil (CAPES) - Código de Financiamento 001.

\section{Referências bibliográficas}

BAUMAN, Zygmunt; DONSKIS, Leonidas. Cegueira moral: a perda da sensibilidade na modernidade líquida. Rio de Janeiro: Zahar, 2014.

DORST, Kees. The core of 'design thinking' and its applications. Design Studies, v. 32, n. 6, p. 521-532, 2011.

DUARTE, Cristiane Rose. Olhares possíveis para o pesquisador em Arquitetura. Revista INTERFACES, v. 1, n. 13, p. 130-145, 2010.

A Empatia Espacial e sua implicação nas ambiências urbanas. Revista PROJETAR - Projeto e Percepção do Ambiente, v. 1, n. 1, p. 68-74, 2016.

DUARTE, Cristiane Rose et al. O Projeto como Metáfora: Explorando Ferramentas de Análise das Ambiências. Rio de Janeiro: ASC/PROARQ/FAU/UFRJ, 2008.

ECO, Umberto. Como se faz uma tese. Lisboa: Editorial Presença, 2007.

ELALI, Gleice. Relações entre comportamento humano e ambiência: Uma reflexão com base na Psicologia Ambiental. In: COLÓQUIO INTERNACIONAL AMBIÊNCIAS COMPARTILHADAS: CULTURA, CORPO E LINGUAGEM, 1., 2009, Rio de Janeiro. Anais... Rio de Janeiro: PROARQ/UFRJ, 2009, p. 1-14.

FISCHER, Gustave-Nicolas. Psicologia social do ambiente. Lisboa: Instituto Piaget, 1994.

GEERTZ, Clifford. A interpretação das culturas. Rio de Janeiro: LTC, 1989. 
GOLLEDGE, Reginald George. Analytical behavioural geography. Londres: Croom Helm, 1987.

GROAT, Linda; WANG, David. Architectural research methods. New Jersey: Wiley, 2013.

GÜNTHER, Hartmut. A Psicologia Ambiental no Campo Interdisciplinar de Conhecimento. Psicologia USP, v. 16, n. 1/2, p. 179-183, 2005.

MERLEAU-PONTY, Maurice. Fenomenologia da percepção. São Paulo: Martins Fontes, 1994 O primado da percepção e suas consequências filosóficas. Belo Horizonte: Autêntica, 2015.

MOSER, Gabriel. Examinando a congruência pessoa-ambiente: o principal desafio para a Psicologia Ambiental. Estudos de Psicologia, v. 8, n. 2, p. 331-333, 2003.

ORTNER, Sherry. Subjetividade e crítica cultural. Horizontes Antropológicos, ano 13, n. 28, p. 375-405, jul./dez. 2007.

PIÑA, Julio Alfonso; ZARAGOZA ORTEGA, Francisco. Psicología Ambiental: ¿Disciplina científica o profesional?. Revista Latinoamericana de Psicología, v. 35, n. 3, p. 329-337, 2003.

SEAMON, David. The phenomenological contribution to environmental psychology. Journal of Environmental Psychology, v. 2, n. 2, p. 119-140, 1982.

SIMMEL, Georg. A metrópole e a vida mental. In: VELHO, Otávio (org.). O fenômeno urbano. Rio de Janeiro: Zahar Editores, 1973, p. 11-25.

THIBAUD, Jean-Paul. Contextualisations sensibles de la ville. In: LEROUX, Martine et al. (orgs.). Compositions sensibles de la ville: Ville émergente et sensorialité. Grenoble: CRESSON, 2000, p. 102-121.

Psicologia ambiental e política ambiental: estratégias de construção do futuro. Psicologia (USP), v. 16, n. 1/2, p. 205-212, 2005.

A cidade através dos sentidos. Cadernos PROARQ, v. 18, n. 1, p. 1-16, 2012a.

Por uma gramática geradora das ambiências. In: SCOCUGLIA, Jovanka (org.). Cidade, Cultura e Urbanidade. João Pessoa: Editora Universitária da UFPB, 2012b, p. 27-70.

TUAN, Yu-Fi. Topofilia: Um estudo da percepção, atitudes e valores do meio ambiente. São Paulo: DIFEL, 1980. 